\title{
A contribution to air quality management in urban industrialized areas
}

\author{
M. Lopes, M. L. Figueiredo, A. Monteiro, J. Ferreira, \\ J. Martins \& C. Borrego \\ CESAM- Centre for Environmental and Marine Studies, \\ Department of Environment and Planning, University of Aveiro, Portugal
}

\begin{abstract}
Despite the increasing concern given to air quality in urban and industrial areas in recent years, particular emphasis on regulation, control and reduction of air pollutant emissions is still necessary to fully characterize the chain emissions air quality - exposure - dose - health effects, for specific sources. In this context, INSPIRAR, a research project started in 2010, was designed to develop a multidisciplinary methodology for air quality, exposure and population health impacts assessment, of industrial pollutants emissions in an industrialized urban area. The Estarreja region was selected as a study case because it has one of the largest chemical industrial complexes in Portugal that has been recently expanded with an increase of its production capacity. This work presents an overview of the first air quality assessment for the region, based on emission inventories and monitoring data. This assessment includes an analysis of trends and the identification and characterization of past air pollution episodes according to the new Air Quality Framework Directive. The contribution of different sources and meteorological conditions to these episodes is investigated. Results show that the most problematic pollutants are ozone and PM10. The advection of contaminated air masses from neighbour regions and adverse weather conditions associated with local emissions, namely industrial activity and road traffic, are the major contributors to air quality degradation in the study region.

Keywords: emissions, air quality, industrial area, air pollution episodes.
\end{abstract}




\section{Introduction}

The intense industrial development from the second half of the 20th century, coupled with population growth and population concentration in urban areas, has enhanced the potential impacts from air pollutant emissions on environment and human health. Despite the increasing concern given to air quality in urban and industrial areas in recent years, particular emphasis on regulation, control and reduction of air pollutant emissions is still necessary to fully characterize the chain emissions - air quality - exposure - dose - health effects, for specific sources. Several scientific studies have evidenced the consequences of the presence of certain pollutants in high concentrations on air quality, exposure and human health. However, the contribution (considering spatial and temporal variation) of industrial activity has not been properly accounted for, in contrast to other sources (e.g. road traffic). Thus, industrialized urban areas present increasing challenges due to the type of pollutants involved (in particular those of industrial origin) and the lack of information on short and long-term exposures and their implications on population health. Moreover, the risks associated with accidental releases of pollutants, resulting in acute exposure to high concentrations with potential impacts on human health, must be also considered.

INSPIRAR project aims to develop a multidisciplinary methodology for air quality, exposure and population health impacts assessment, from the emission of industrial pollutants in an industrialized urban area. The methodology will be applied to the Estarreja region, an urban area that has one of the largest chemical complexes in Portugal, currently under expansion. The Estarreja Chemical Complex (ECC), located north of urban city centre, is now composed by several chemical units working in different fields of chemistry. Therefore, and over the last years, Estarreja region has been subject to impacts from industrial and urban activities reflected on atmospheric pollution phenomena.

The methodology to be adopted in INSPIRAR consists on the implementation of modelling tools to quantify industrial air pollution and human exposure of two different groups - industrial workers and general population. To accomplish this goal, it is essential to perform a detailed environmental characterization of Estarreja region as a starting task, focusing on air pollutants emissions (resulting from industrial activity and other relevant sources existing in the region) and air quality evaluation in the study area. This paper presents the first air quality assessment for the region, based on historical monitoring data and emission inventories. This assessment includes an analysis of trends and the identification and characterization of past air pollution episodes according to the new Air Quality Framework Directive. The contribution of different sources and meteorological conditions to these episodes is investigated. The results from this compilation will be used in the environmental and epidemiological approaches for population and individual exposure study, as they constitute necessary inputs for the development and application of numerical models for air pollutants dispersion, which will be applied for specific scenarios in order to evaluate short and long-term air quality and human exposure impacts. 


\section{Study area characterization}

Estarreja is a growing urban area with an interesting location in the Portuguese coastland and crossed by important road traffic and rail national networks. A characterization of the past and current situation of atmospheric pollutants emissions and air quality monitoring in Estarreja will be presented as tools for air quality assessment.

\subsection{Atmospheric Emissions}

According to the European Environment Agency data for the period 1990-2008 [1], Portuguese national emissions have been decreasing along the past years. In 2008, national emissions were under the national emission ceiling defined for 2010 for $\mathrm{NO}_{\mathrm{x}}, \mathrm{SO}_{2}$ and $\mathrm{NH}_{3}$. The $\mathrm{SO}_{2}$ emissions trend shows a significant reduction (64.6\% between 1990 and 2008), 33\% under the $\mathrm{SO}_{2}$ national emission ceiling [1]. However, despite the reduction trend on NMVOC emissions, 34\% between 1990 and 2008, they were still 9.7\% above the national emission ceiling [1]. NOx emission trend shows an important increase in the 90's (+23.8\%). From 2000, NOx emissions stabilized and even tended to decrease in the last few years. Between 1990 and 2008, NO2 emission variation was $+3.2 \%$ [1]. $\mathrm{NH}_{3}$ emissions show a slight decreasing trend (-20.3\%). In 2008, $\mathrm{NH}_{3}$ emissions were $43.8 \%$ under the national ceiling.

A more detailed analysis has been performed for Estarreja municipality, based on the national emission inventory reported by the Portuguese Environment Agency (APA) for the years 2003, 2005, 2007, 2008 [2]. Figure 1 shows the evolution of various pollutants over the 4 years analyzed.

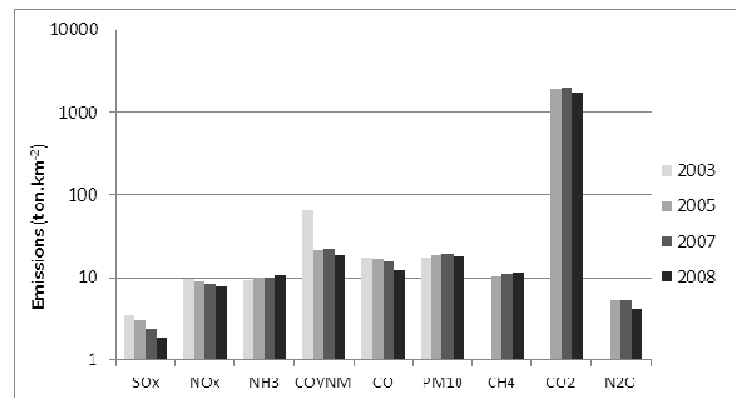

Figure 1: $\quad$ Emission inventory of Estarreja [2].

Globally, pollutant emission trends for Estarreja are coincident with the ones at national level. However, $\mathrm{NH}_{3}$ emissions present an increase of about $8 \%$ which may be due to the existence of a chemical plant on the industrial complex which uses $\mathrm{NH}_{3}$ as raw material for production of nitric acid. An analysis by activity sectors was also performed based on 2008 national emission inventory, allowing identifying the contribution from each activity sector to total emissions. 
This analysis evidences the major contribution of industrial activities to the atmospheric pollutants, accounting around $80 \%$ of total emissions in the municipality of Estarreja, in 2008. Indeed, industrial processes represent $71 \%$ of $\mathrm{NH}_{3}$ amount while agriculture only represents $28 \%$ of $\mathrm{NH}_{3}$ total emissions and they also represent the major weight for PM10 (95\%), $\mathrm{SO}_{2}(92 \%)$ and $\mathrm{N}_{2} \mathrm{O}$ $(89 \%)$. Despite the major contribution from road traffic $(58 \%)$ to $\mathrm{NO}_{2}$ emissions, industrial activities still weight greatly, namely, $26 \%$ emission are from industrial combustion and $8 \%$ from industrial processes. Total $\mathrm{CO}_{2}$ emissions in 2008 showed a 54\% weight from industrial combustion and only $37 \%$ contribution from road traffic. The great contributors to NMVOC emissions are also industrial processes and solvent use (68\%). $80 \%$ of $\mathrm{CH}_{4}$ emissions came from waste treatment and $15 \%$ from agriculture.

\subsection{Air quality network}

The Air Quality Network of Estarreja dates from 1985. Until 2005, there were 2 active air quality stations at Estarreja, namely, an industrial suburban station named Teixugueira and Avanca rural background station. Both stations were integrated at Estarreja area of influence. The Avanca air quality station was in operation from January 1985 till March 2005. It was located north of the industrial complex and monitored $\mathrm{SO}_{2}, \mathrm{NO}_{\mathrm{x}}, \mathrm{O}_{3}, \mathrm{PM} 10$ and PM2.5 air concentrations. Teixugueira air quality station started its operation in 1990. This station is located south of the industrial complex and monitors $\mathrm{SO}_{2}, \mathrm{NO}_{\mathrm{x}} \mathrm{O}_{3}$, PM10 and PM2.5 concentrations.

\section{Air quality assessment}

\subsection{Fulfilment of the legislation}

The first step of an air quality assessment should be the analysis of the legislation fulfilment. The new EC 2008/50 Framework Directive compiles all the air quality parameters and pollutants. This analysis, for each pollutant, is presented according to each limit value and threshold defined by legislation.

Figure 2 presents the results for $\mathrm{SO}_{2}, \mathrm{O}_{3}$ and PM10 for each legislated limit/threshold value. Only these three pollutants, that registered exceedances during the study period 2000-2009, are presented. For $\mathrm{SO}_{2}$, hourly and daily limit values are examined according to what is legislated for human health protection (Fig. 2(a) and (b)). For $\mathrm{O}_{3}$, legislation defines an 8-hour average daily maximum limit value and also an hourly information and alert threshold (Fig. 2(c) and (d)). For PM10, a short-term (daily average) and long-term (annual average) limits are defined and investigated in Figure 2(e) and (f).

As already mentioned, exceedances to limit value and target value of $\mathrm{SO}_{2}$, PM10 and $\mathrm{O}_{3}$ concentrations were verified during the study period. Most critical pollutants like PM10 and $\mathrm{O}_{3}$ surpass the defined goals consecutively. For example, $\mathrm{O}_{3}$ information threshold was exceeded in all years (except 2000) together with the target value of the daily maximum 8-hour average. 


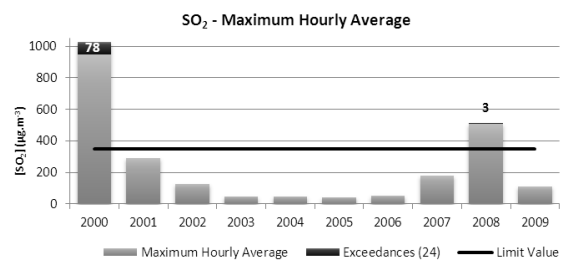

(a)

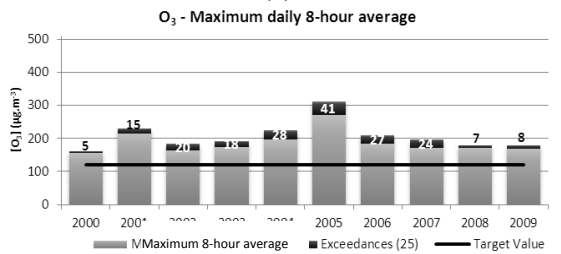

(c)

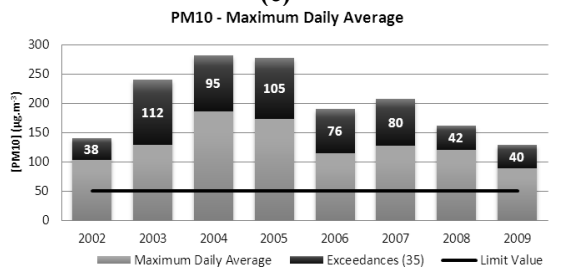

(e)

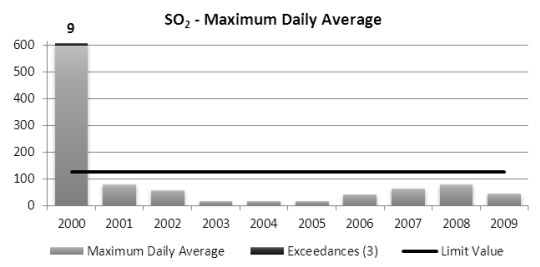

(b)

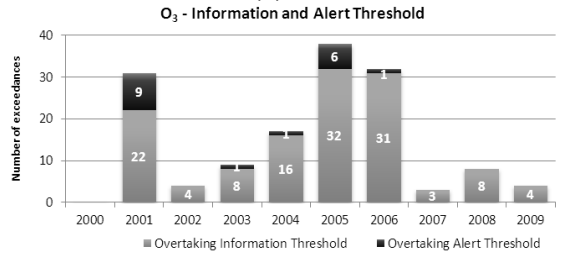

(d)

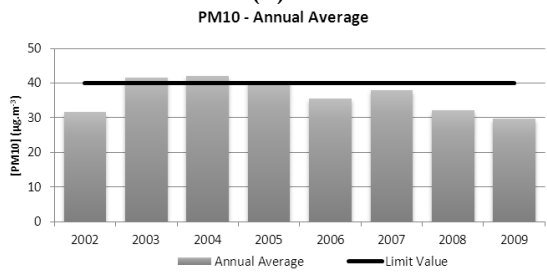

(f)

Figure 2: Analysis of the fulfilment of the legislation limit (a), (c), (e) and threshold (b), (d), (f) values for (a), (b) $\mathrm{SO}_{2}$, (c), (d) $\mathrm{O}_{3}$ and (e), (f) PM10 during the period 2000-2009.

\subsection{Air quality tendencies}

In addition to the legislation fulfilment, a trend analysis was also performed in order to evaluate the evolution of the several pollutants concentration levels within the 10-year study period. Figure 3 shows this evolution in terms of percentiles, median, maximum and minimum values for the main critical pollutants in terms of human health effects $-\mathrm{SO}_{2}, \mathrm{NO}_{2}, \mathrm{O}_{3}, \mathrm{PM} 10$ and PM2.5 within the study time period.

This statistical analysis shows that there is no evident trend for $\mathrm{NO}_{2}$ and $\mathrm{O}_{3}$, but a decrease is verified for PM (both PM10 and PM2.5) since 2005.

Regarding $\mathrm{SO}_{2}$, an extraordinary peak was monitored in 2000 reaching $600 \mu \mathrm{g} . \mathrm{m}^{-3}$, but during the remaining years maximums values were inferior to $100 \mu \mathrm{g} \cdot \mathrm{m}^{-3}$.

In what concerns $\mathrm{NO}_{2}$, median values of $10-20 \mu \mathrm{g} \cdot \mathrm{m}^{-3}$ are registered at this site with maximum values of $90 \mu \mathrm{g} \cdot \mathrm{m}^{-3}$ observed in 2006 and 2009. For $\mathrm{O}_{3}$, the most critical values were registered during 2001 and 2005, with maximums higher than $300 \mu \mathrm{g} . \mathrm{m}^{-3}$. Background values (median) are close to $50 \mu \mathrm{g} . \mathrm{m}^{-3}$.

In respect of particulate matter, the decrease trend since 2005 can be quantified in about $50 \%$ of reduction in both median and maximum levels, between 2005 and 2009. 


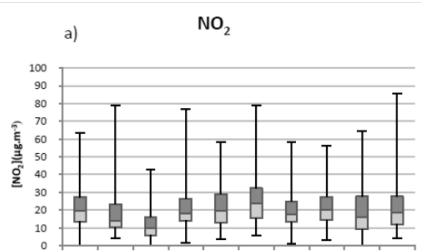

2000200120022003200420052005200720082009

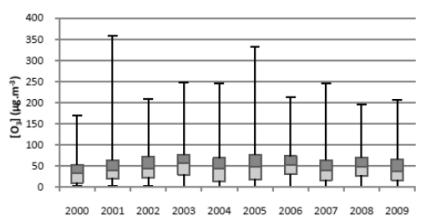

2000200120022003200420052006200720082009

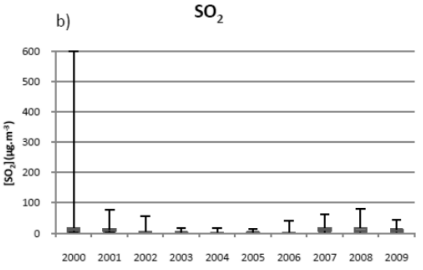

d) PM10

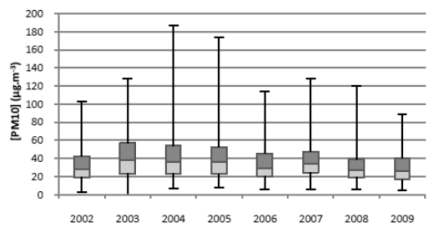

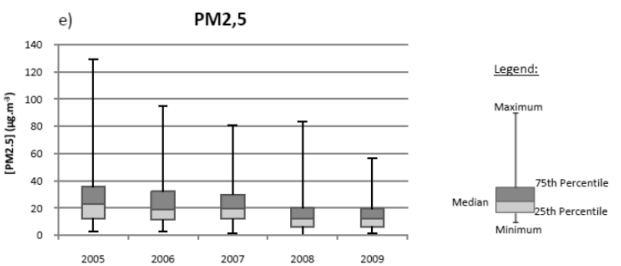

Figure 3: Evolution of the percentiles, median, maximum and minimum concentration values for (a) $\mathrm{NO}_{2}$, (b) $\mathrm{SO}_{2}$, (c) $\mathrm{O}_{3}$, (d) PM10 and (e) PM2.5 during the study period 2000-2009.

\subsection{Air quality index}

The air quality index (AQI) was created with the purpose to integrate the several pollutants assessment and to facilitate the comprehension and dissemination of the air quality information by the general public. This index takes into account the five major air pollutants regulated and their limit/threshold values. The most critical pollutant, in terms of the air quality standards, is responsible for the global index colour (to see more: www.qualar.org; www.airnow.gov). The analysis of the AQI (number of days for each index class) has been performed for the Estarreja region for the period 2003-2008. It was verified that the colour green (Good AQI) is the most frequent (40-60\% of days) air quality level during the study period. The percentage of "Weak" and "Bad" air quality index days is about $10-30 \%$, with a slight decrease trend over the last years (2006-2008), and an increase on the days with "Very good" AQI.

This qualitative analysis gives an important overview in terms of the air quality over the study region, but it is, however, limited in terms of pollutant identification and magnitude of the pollution episodes. A detail analysis, combining monitoring and modelling data is required to investigate the origin and the sources of the bad air quality days registered within this industrial area. 


\section{Air pollution episodes}

\subsection{Methodology}

Besides the "Good" overview that characterized the air quality over the study region, several "bad" AQI days were registered and we will now focus on them. An episode for each major critical pollutant - $\mathrm{SO}_{2}, \mathrm{O}_{3}$ and PM10 - was selected and further investigated.

The methodology of [3] was adopted, and this investigation was initiated with an air quality and meteorological data time series analysis, followed by a synoptical characterization and simulation of air masses back-trajectories (HYSPLIT model). For PM, the DREAM model was also applied for the simulation of the dispersion and transport of the Saharan desert dust, one of the main sources of dust events frequently recorded over Portugal and Spain [4, 5].

Pollutant concentration data was crossed with meteorological parameters to enable understanding the correlations between pollution episodes and meteorological conditions. Available data from the monitoring station located at the University of Aveiro was used for this meteorological analysis.

The analysis was complemented with a synoptical description of each episode (through 500hP geopotential high and surface pressure charts [6]) and simulation of air masses backtrajectories using the Hybrid Single-Particle Lagrangian Integrated Trajectory Model (HYSPLIT), developed by the National Oceanic and Atmospheric Administration (NOAA) Air Resources Laboratory (ARL) [7]. HYSPLIT is a complete system that uses meteorological grid data based on prediction meteorological models to calculate trajectories, dispersion fields and gases and particulate matter deposition [8]. The meteorological data used in this study came from NCEP/NCAR (National Centers for Environmental Prediction National Center for Atmospheric Research) reanalysis global project. To identify the air masses origin, 3 day kinematics backtrajectories were calculated from 3 different altitude levels (100, 500 and $1000 \mathrm{~m} \mathrm{AGL)}$.

To investigate the contribution of dust natural events to the high episodes of PM10, 2 types of natural events were analyzed: emissions from forest fires occurred near the study area and transport of Saharan dust. For this, the BSC-DREAM8b (Dust REgional Atmospheric Model) model, operated by Barcelona Supercomputing Center [9] was applied. This model incorporates parameterizations of most important phases of particulate matter lifecycle, such as production, dispersion, advection and removal. The effect of distribution by size in dispersion of aerosols is also considered [9]. An episode for $\mathrm{O}_{3}$ and PM10 pollutants is illustrated below.

\subsection{Ozone episode}

Between $27^{\text {th }}$ and $31^{\text {st }}$ May 2001 peaks of $\mathrm{O}_{3}$ concentration with values beyond $300 \mu \mathrm{g} . \mathrm{m}^{-3}$ were registered at Teixugueira station. The comparative analysis of each pollutant concentration time series for this time period - Figure 4 suggests an $\mathrm{NO}_{2}$ consumption for photochemical production of $\mathrm{O}_{3}$. 


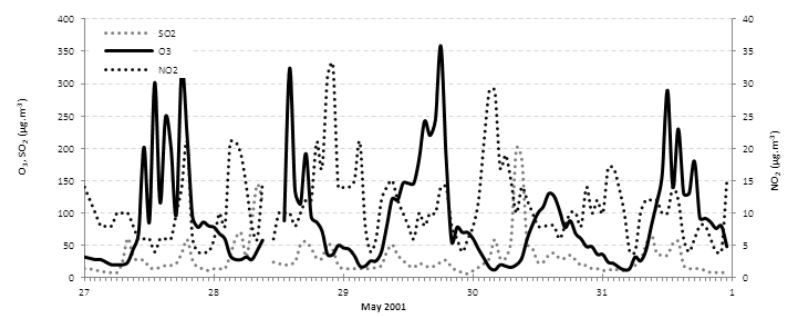

Figure 4: $\quad$ Monitored $\mathrm{SO}_{2}, \mathrm{NO}_{2}$ and $\mathrm{O}_{3}$ concentrations between $27^{\text {th }}$ and $31^{\text {st }}$ May 2001.

During this period, $\mathrm{O}_{3}$ exhibits a typical photochemical behaviour, with an increase of its concentration after midday and a significant decrease during the night. In Figure 5 the meteorological parameters registered during this episode are analyzed: $\mathrm{O}_{3}$ concentration $v s$ temperature and $v s$ wind direction and speed.

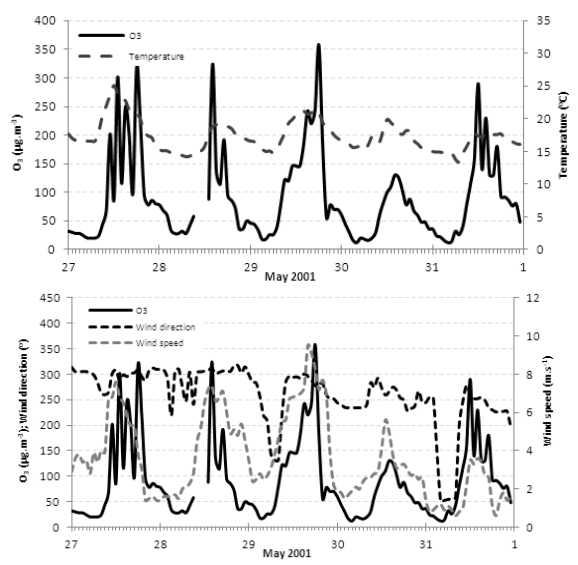

Figure 5: Meteorological parameters (temperature, wind speed and direction) and $\mathrm{O}_{3}$ concentration measured between $27^{\text {th }}$ and $31^{\text {st }}$ May 2001.

It should be noticed that the moderate temperatures observed $\left(<25^{\circ} \mathrm{C}\right)$, not typical of a photochemical behaviour, were registered at the coastal station of Aveiro and could not be representative of Estarreja region. Nevertheless, when comparing ozone peaks with temperature there is a delay in time between maximum temperature and maximum $\mathrm{O}_{3}$ concentration. The highest peak from $27^{\text {th }}$ and the $29^{\text {th }}$ peak were registered at 18:00. Therefore, besides local formation of $\mathrm{O}_{3}$, this analysis suggests the existence of $\mathrm{O}_{3}$ transport from north coastal zone. The wind and $\mathrm{O}_{3}$ patterns are consistent over the several episode days, with an increase in wind speed with high concentrations with winds from NW/N. This fact corroborates the hypothesis of transport of this pollutant (and/or its precursors) from urban coastal area. Figure 6 presents the backtrajectories obtained for these days. 


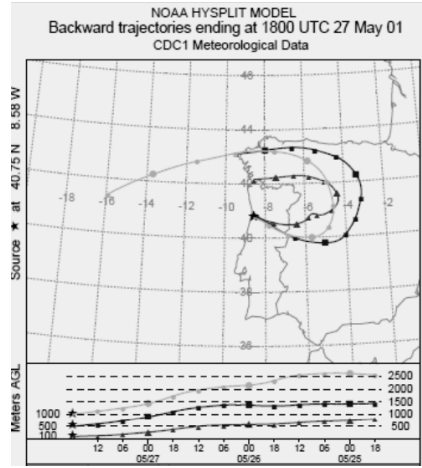

(a)

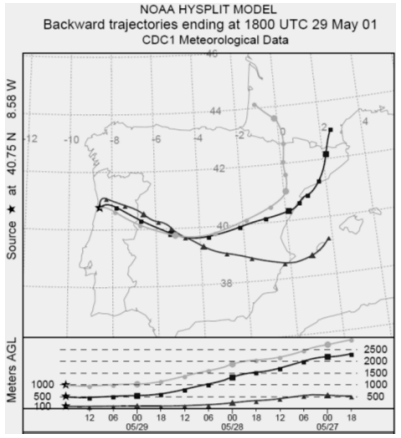

(c)

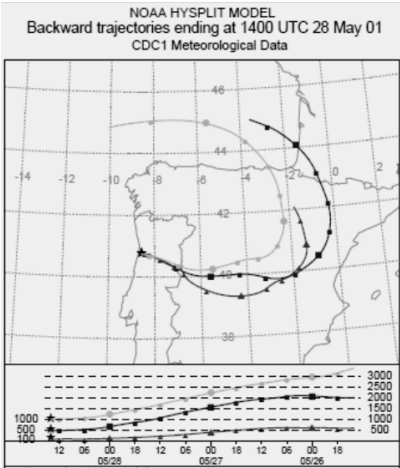

(b)

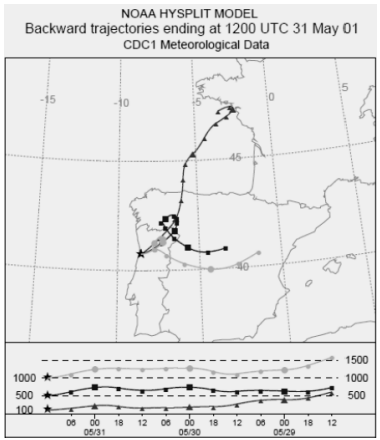

(d)

Figure 6: Backtrajectories given by HYSPLIT model to $27^{\text {th }}$ May (a), $28^{\text {th }}$ May (b), $29^{\text {th }}$ May (c) and $31^{\text {st }}$ May (d).

The backtrajectories indicate that air masses have a similar pattern in all episode days, showing a synoptical circulation from E/NE, typical of anticyclonic conditions over Iberian Peninsula. Besides this synoptical E/NE component, there is a north surface circulation that is responsible for the local dispersion and transport of pollutants. Avanca station data reveal also high $\mathrm{O}_{3}$ concentration values over this episode period, reinforcing the hypothesis of $\mathrm{O}_{3}$ transport. Nevertheless, Teixugueira station registered higher magnitude values suggesting an additional formation of $\mathrm{O}_{3}$ probably caused by precursors emitted by Estarreja Chemical Complex. To obtain more accurate results about the concentration peaks origin a deeper study should be held using numerical modelling tools [10-12].

\subsection{PM10 episode}

Between $21^{\text {st }}$ and $24^{\text {th }}$ January 2004, high values of PM10 concentration were measured in Teixugueira station, with values exceeding $300 \mu \mathrm{g} \cdot \mathrm{m}^{-3}$. In Figure 7 a comparison of the several pollutants measured during this episode is made.

During the study period a delay in some concentration peaks of $\mathrm{NO}_{2}$ and PM10 is verified. This fact indicates that there is a possible industrial origin 


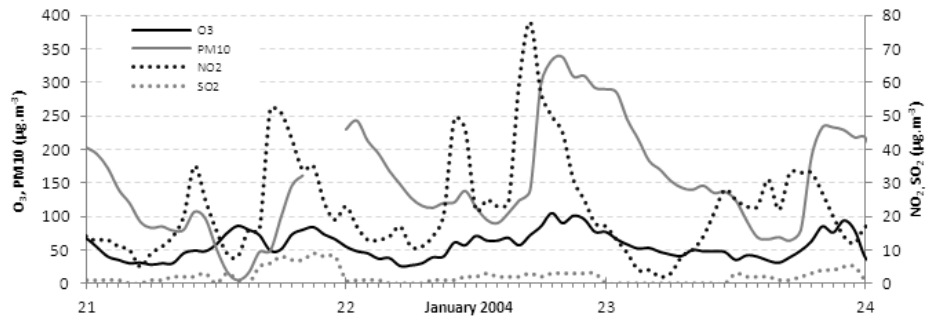

Figure 7: $\quad \mathrm{SO}_{2}, \mathrm{NO}_{2}, \mathrm{O}_{3}$ and PM10 concentrations monitored in Teixugueira between $21^{\text {st }}$ and $23^{\text {rd }}$ January 2004.

causing this episode. To understand the impact of Sahara desert dust in this episode, images of aerosol index were analyzed for this day, given by BSCDREAM8b and NASA-TOMS [15]. Figure 8 exhibits the results given by each model for $22^{\text {nd }}$ January 2004.

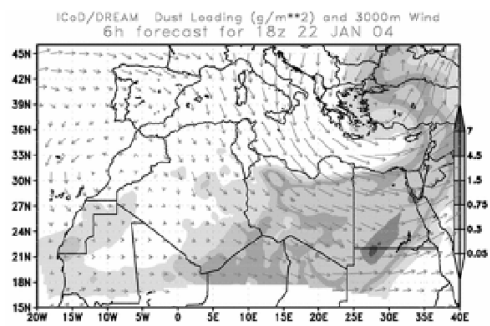

(a)

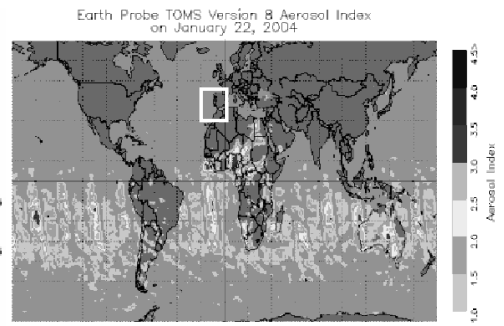

(b)

Figure 8: Aerosol Index given by DREAM model (a) and by NASA-TOMS model (b) for $22^{\text {nd }}$ January $2004[9,15]$.

The analysis of both maps does not reveal any influence of Saharan dust during this episode. Taking into account that this is a winter episode and the peak occurs at night this can indicate a domestic combustion influence. On the other hand, the highest concentration value registered at 20:00 reveals also a possible contribution from traffic.

In Figure 9, the meteorological time series indicate a low wind speed at the time of occurrence of peak values, indicating a situation of calm that favours

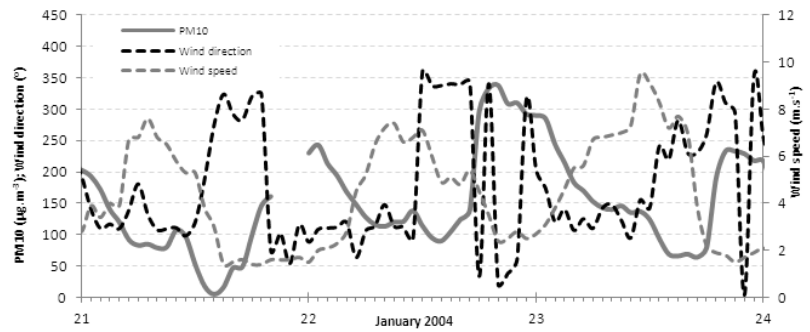

Figure 9: Meteorological parameters (wind speed and direction) and PM10 concentration measured between $21^{\text {st }}$ and $23^{\text {rd }}$ January 2004. 
thermal inversion $[13,14]$. These results reinforce the existence of stable atmospheric conditions that impede the pollutants dispersion and favour its accumulation in the atmosphere, confirmed by the high background concentration values observed during the 4 days. Besides that, both Avanca and Teixugueira stations show a similar PM10 concentrations behaviour, confirming the hypothesis of non-dispersion and accumulation of PM10 in the atmosphere during the night.

The air masses backtrajectories from $22^{\text {nd }}$ January, represented in Figure 10, have distinct directions for 1:00 and 20:00. For the 1:00 peak air masses have N/NE direction for all heights (100, 500, $1000 \mathrm{~m}$ AGL). In the 20:00 peak the circulation pattern is not identical at different heights, indicating the existence of local/surface recirculation. This is supported by the wind direction profile of Figure 11 that indicates a dominant circulation of N/NE, which can point to the local provenance (industrial and urban) of this PM during this episode.

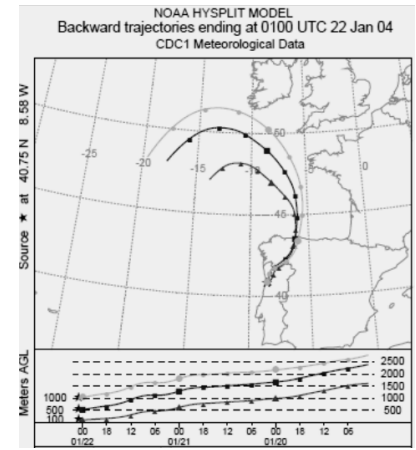

(a)

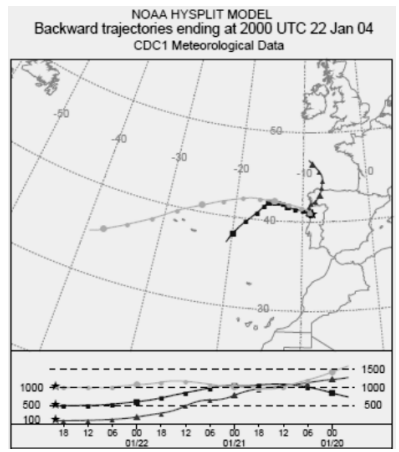

(b)

Figure 10: Backtrajectories given by HYSPLIT model to $22^{\text {nd }}$ January 2004 .

\section{Final remarks}

Estarreja is an important industrialized urban area in Portugal. During the last decades, several studies have been carried out in order to assess the impact of emission sources and to prevent air quality degradation. Since 1985 air quality continuous monitoring is in operation, covering the most important legislated pollutants.

In the last decade, pollutant emission trends to decrease for almost all pollutants analysed. However, $\mathrm{NH}_{3}$ emissions present an increase of about $8 \%$ which may be related to the production of nitric acid in the industrial complex. This analysis of the emission inventory evidences the major contribution of industrial activities to the atmospheric pollutant emissions, accounting around $80 \%$ of total emissions in the municipality of Estarreja in 2008.

During the study period (2000-2009) exceedances to limit values and target values of $\mathrm{SO}_{2}, \mathrm{PM} 10$ and $\mathrm{O}_{3}$ concentrations were verified. Most critical pollutants like PM10 and $\mathrm{O}_{3}$ surpass the regulated standards consecutively. For 
example, $\mathrm{O}_{3}$ information threshold was exceeded in all years (except 2000) together with the target value of the daily maximum 8 -hour average.

The analysis performed to different pollution episodes reveals the importance of different phenomena, from both natural and anthropogenic influence. Some episodes can be related with local emissions, namely industry and traffic, and specific meteorological conditions (atmospheric stability; high temperature and radiation, leading to photochemical production). Advection and long range transport (including dust from Sahara desert) can also play an important role.

Further modelling studies should be carried out in order to better understand the importance of local emissions and different activities on local air quality.

\section{Acknowledgements}

The authors wish to thank the financial support of the PACOPAR. Thanks are extended to the Portuguese Science Foundation for the financial support through the Project INSPIRAR (PTDC/AAC-AMB/103895/2008), for the post doc grant of A. Monteiro (SFRH/BPD/63796/2009) and J. Ferreira (SFRH/BPD/40620 /2007).

\section{References}

[1] EEA, 2010. Portugal air pollutant emissions country factsheet. Copenhagen. European Environment Agency.

[2] APA, 2010. Atmospheric pollutant emissions by municipality, 2008. Acidifying and eutrophying gases, ozone precursors, partículate matter, heavy metals and greenhouse gases Amadora, Agência Portuguesa do Ambiente (Portuguese Environmental Agency).

[3] Monteiro, A., Strunk, A., Carvalho, A., Tchepel, O., Miranda, A. I., Borrego, C., Saavedra, S., Rodríguez, A., Souto, J., Casares, J. and Elbern, H. 2010. Investigating a high ozone episode in a rural mountain site (north of Portugal). Submitted to Atmospheric Chemistry and Physics.

[4] Rodriguez S.; Querol, X.; Alastuey, A.; Kallos, G. and Kakaliagou, O., 2001. Saharan dust contributions to PM10 and TSP levels in Southern and Eastern Spain. Atmospheric Environment 35, 2433-2447.

[5] Wagner, F.; Bortoli, D.; Pereira, S., Costa, M.J., Silva, A.M., Weinzier, B., Esselborn, M., Petzold, A., Rasp, K., Heinold, B. and Tegen, I., 2009. Properties of dust aerosol particles transported to Portugal from the Sahara desert. Tellus, 61B, 297-306.

[6] URL: www.wetterzentrale.de/topkarten/fsgfsmeur.html

[7] Draxler, R. R. \& Rolph, G. D. 2011. HYSPLIT (HYbrid Single-Particle Lagrangian Integrated Trajectory) [Online]. NOAA Air Resources Laboratory, Silver Spring, MD. Available at: http://ready.arl.noaa.gov /HYSPLIT.php

[8] URL: www.arl.noaa.gov/HYSPLIT_info.php

[9] URL: www.bsc.es/projects/earthscience/DREAM/ 
[10] Borrego, C.; Miranda, A.; Coutinho, M.; Ferreira, J. and Carvalho, A. 2002. Air quality management in Portugal: example of needs and available tools. Environmental Pollution, 120, 115-123.

[11] Monteiro, A., Miranda, A., Borrego, C. and Vautard, R. 2007. Air quality assessment for Portugal. Science of the Total Environment, 373, 22-31.

[12] Reid, N., Misra, P. K., Amman, M. \& Hales, J. 2007. Air quality modelling for policy development. Journal of Toxicology and Environmental HealthPart A, 70 (3-4), p. 295-310.

[13] Oke, T. R. 1987. Boundary layer climates, Routledge.

[14] Seinfeld, J.H., Pandis, S.N., 1998. Atmospheric Chemistry and Physics: From air pollution to climate change. John Wiley \& Sons, New York. ISBN: 9780471178163.

[15] URL: http://toms.gsfc.nasa.gov/aerosols/ 